\title{
CLIMATOLOGICAL EFFECTS ON THE BREEDING OF TERNS
}

\author{
Graham Quartly ${ }^{1}$, Sébastien Jaquemet ${ }^{2}$, Matthieu Le Corre ${ }^{2}$, David Monticelli ${ }^{3,4}$ \& Jaime Ramos ${ }^{5}$ \\ ${ }^{1}$ National Oceanography Centre, Southampton, UK, ${ }^{2}$ Université de la Réunion, Réunion, France, \\ ${ }^{3}$ Royal Belgian Institute of Natural Sciences, Brussels, Belgium, ${ }^{4}$ Lab. of Tropical and Subtropical \\ Forestry, U. of Gembloux, Belgium, ${ }^{5}$ Institute of Marine Research, U. of Coimbra, Portugal
}

\begin{abstract}
The physical circulation in the Western Indian Ocean controls the supply of nutrients, and this, combined with the stability of the surface layer and the availability of sunlight controls the primary production. In this note, we review two papers' findings on how the physical conditions ultimately impact upon the breeding of terns, a marinetop predator in the region. Rather than trace causal links through the food chain, we show empirical connections between avian breeding and the environmental conditions, all of which appear statistically significant.
\end{abstract}

Index Terms - Climate variability, Western Indian Ocean, Chlorophyll, Sterna, Breeding

\section{BACKGROUND}

Our study area spans a number of tropical islands in the Western Indian Ocean, spanning a latitudinal range of $20^{\circ}$, each of which hosts a major colony of seabirds. Although some are manned as military posts or research stations, human presence is low so that neither humans nor their animals seriously disrupt the birds' breeding. Life theory predicts that birds will adopt a breeding strategy to optimise their chances of rearing young, which, in the absence of external forcing, would mean attempting breeding as often as possible. For most land-based birds in high latitudes, "spring" is the time associated with breeding on account of the increase in temperature and the greater availability of food. This paper considers the situation in a tropical marine environment, where it is less clear which environmental cues will control the timing.

\subsection{Oceanographic circulation}

Figure 1 shows the mean chlorophyll concentration (CC) for July-August and the general surface circulation. The key features of note in the $\mathrm{CC}$ are associated with the coastal upwelling to the south and west of Madagascar, major riverine input in the west of the Mozambique Channel, and broad upwelling in the open ocean just south of the equator due to Ekman suction i.e. the divergence of surface flows induced by the wind. The pattern shown is during the middle of the southwest monsoon season; the opposite phase of the monsoon reverses some of the currents in the Arabian Sea, but south of the equator the effects are minor, except that the eastward-flowing SECC then lies further south $\left(\sim 2^{\circ} \mathrm{S}\right)$ [1]. During the NE monsoon the winds induce downwelling in the Seychelles area, and CC levels are consequently much reduced [2]. The flow within the Mozambique Channel is dominated by large anticyclonic eddies [3], which often advect strands of high-chlorophyll water in to mid-channel [4]

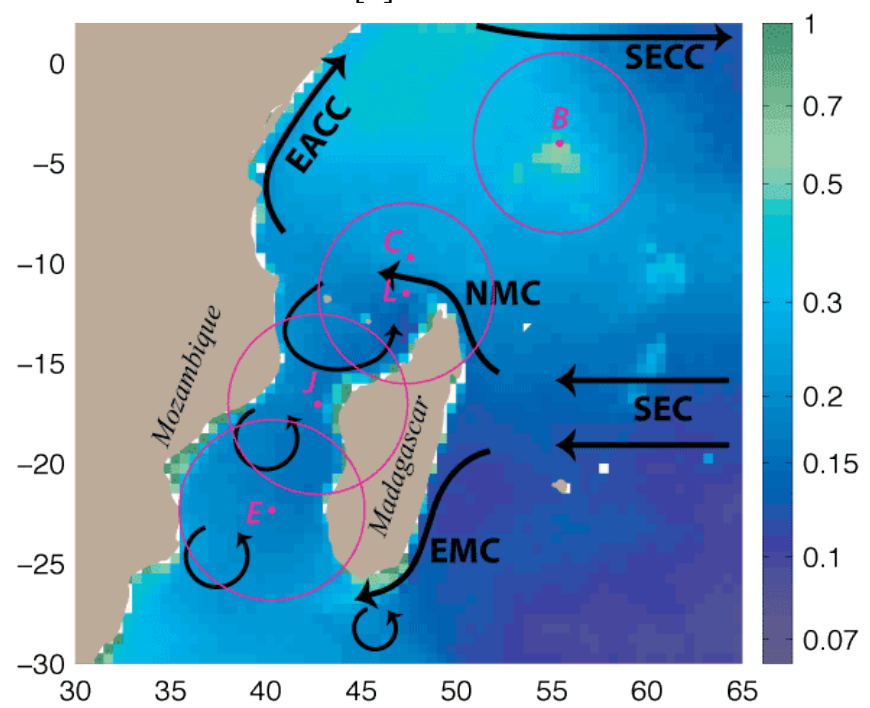

Fig. 1. Mean chlorophyll concentration (CC) in $\mathrm{mg} \mathrm{m}^{-3}$ for JulyAugust. The schematic of the surface currents shows South Equatorial Current (SEC), East Madagascar Current (EMC), North Madagascar Current (NMC), East Africa Coastal Current (EACC) and South Equatorial Countercurrent (SECC). The islands marked are Europa (E), Juan de Nova (J), Lys Island in the Glorieuses (L), Cosmoledo (C) and Bird Is. in the Seychelles (B).

\subsection{Sooty and roseate terns}

Terns are long-lived marine birds, feeding on the epipelagic fauna. mostly fish that are typically forced by schools of predators into the surface layers of the ocean. Sooty terns (Sterna fuscata) can live up to 30 years, and an adult weighs $\sim 200 \mathrm{~g}$ and has a wingspan of $\sim 90 \mathrm{~cm}$. They are found in tropical regions all around the world; our study has focused on large breeding colonies on Europa, Juan de Nova, Lys 
and Bird Island (see Fig. 1). Three of these sites have been regularly visited by the authors, whilst many records exist for the 4th site. Sooty terns feed as a flock, with foraging distances of up to $500 \mathrm{~km}$ being possible (illustrated by circles in Fig. 1).

Roseate terns (Sterna dougallii) are slightly smaller $(100 \mathrm{~g}, 79 \mathrm{~cm})$, with an expected lifespan of 26 years. Our colony of interest for this species is on Aride Island in the Seychelles, upon which the birds settle in March-April in preparation for breeding. They can travel long distances during migration, but when nesting their maximum foraging radius is about $50 \mathrm{~km}$.

\subsection{Environmental data}

The records of environmental conditions used in this analysis are i) sea surface temperature (SST) from IGOSS, and ii) $\mathrm{CC}$ at $9 \mathrm{~km}$ resolution from the SeaWiFS sensor. Considering $\mathrm{CC}$ to be a proxy for available prey, we use a measure of the peak productivity within the foraging area. This was calculated for every fifth of a month (5-6 days); in some cases this measure was highly variable, such as when patches of high productivity water were advected past the islands by eddies. We also made use of two climatic indices: Multi-variate ENSO Index (MEI) and Dipole Mode Index (DMI). Further details on the provenance, derivation and interpretation of all our data can be found in refs $[2,5]$.

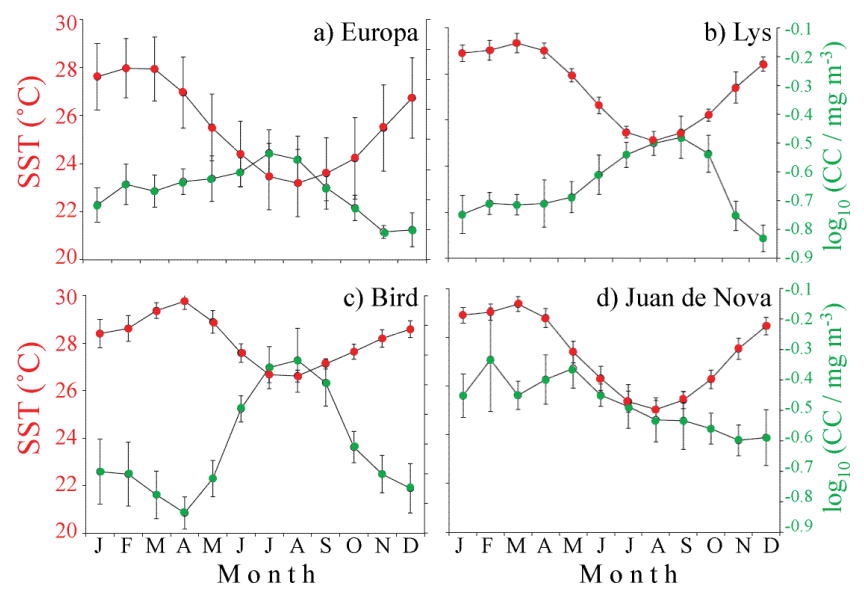

Fig. 2. Monthly means of SSTand CC for the 4 islands. (Based on Fig. 2 from [5].)

\section{ANNUAL CYCLES}

As stated in section 1.1, there are annual changes in the winds and currents (and of course the azimuthal position of the sun), and these lead to annual cycles of SST and CC (Fig. 2). All 4 sites show a peak in SST in March-April (southern hemisphere autumn), although the range is slightly less for Bird Island, which lies close to the equator. The interannual variations (indicated by the error bars on the monthly means) is greatest for the southernmost (Europa).
As far as CC is concerned, three show a clear annual cycle, peaking in early to mid spring; however the causes differ, with maximal Ekman suction explaining the peak for Bird Island, whereas the others may relate to the increased sunlight and the return of stratification to the water column. The behaviour at Juan de Nova is unusual in that the CC peak is in February, when SST is highest.

Over the past decade we have made a number of trips to $\mathrm{E}, \mathrm{J}$ and $\mathrm{L}$ recording the state of development of the sooty tern chicks found there. By recording wing span and using recognised growth rates for terns [6], and subtracting a typical incubation period of 28 days, we deduce the likely laying dates. Typically all the birds in a colony lay within a short period; the typical standard deviation of observations being $\sim 8$ days (see [5] for full details). In the case of Bird Island, we make use of historical records of observations by Feare $[6,7]$

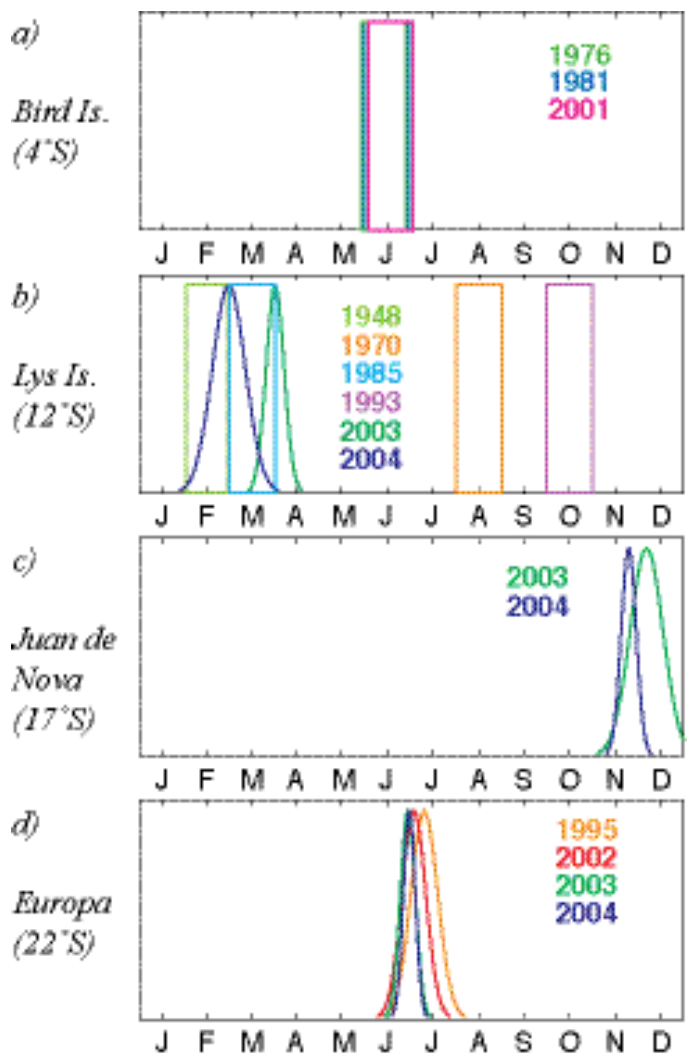

Fig. 3. Date of egg-laying for each year of observation. Some, records only give the month; for the others, the authors recorded actual dates, giving a mean and standard deviation of observations (see [5]), here portrayed by a Gaussian curve. (Tickmarks indicate middles of months.)

The particularly interesting aspect of these results (Fig. 3 ) is that the same bird species appears to adopt 3 different breeding strategies across these 4 islands - for both the southernmost and northernmost the breeding is exclusively in winter, for Juan de Nova, the breeding is always in 
summer, whilst for Lys it is non-seasonal. Note, although not adopting a regular annual cycle, the birds on this island still breed at the same time as one another rather than uniformly throughout the year. This "colonial breeding" provides a gain in foraging efficiency through intra-flock communications $[8$ and protection for chicks on the colonies].

For E, J and B the seasonal breeding precedes the peak in $\mathrm{CC}$, and thus the inferred abundance of prey. Egg-laying appears to be triggered by sharp changes in ambient temperature, as has been noted for other species [9]. However, Lys exhibits equally strong changes in SST and $\mathrm{CC}$, so this cannot be the full picture. Rather, prey availability there must be more uniform year round, so that the terns can choose a breeding cycle of less than 12 months. (Note, non-seasonal breeding is also noted for sooty terns on Ascension Island [10] in the tropical Atlantic.) The interpretation for Lys is further confounded by the many observations of regular winter breeding at Cosmoledo (C). If terns on both $\mathrm{L}$ and $\mathrm{C}$ foraged freely within $500 \mathrm{~km}$ of their bases, then similar results would be expected at each. This suggests that foraging area may also be limited by the existence of neighbouring colonies.

\section{INTERANNUAL VARIATIONS}

A more detailed study has been made of roseate terns on one particular island: Aride (which is close to B). This involved lengthy visits to the colony, with measuring of eggs and recording of clutch sizes from typically 600-1000 nests, recording hatching rates, and growth and fledging success of the chicks (see [2] for full details). For this study we wanted to look at interannual changes in breeding performance, and how they related to the environmental conditions. Data were collected for 8 years (1998-2005), which included two seasons of almost complete breeding failure. The various measures of breeding success (clutch size, mean egg volume, no. of chicks fledged per nest) were regressed against both local environmental conditions (SST and CC) and large-scale climatic indices (MEI and DMI).

It was found, not surprisingly, that the earlier in the year the group bred the more successful they were (no. of chicks fledged), but also that egg-laying was timed to precede the local CC peak by 60-70 days, which corresponds to the time needed for hatching and fledging of chicks. Roseate terns only lay one or two eggs in a season, but the mean clutch size was strongly correlated with the rate of increase of CC in the vicinity (Fig. 4). For overall productivity, an equally important factor was MEI (see Table 3 of [2]), which is a measure of El Niño/La Niña activity recorded in the tropical Pacific! We had initially expected the Indian Ocean Dipole (summarised by DMI) to be more significant, but note that the Seychelles only lie on the edge of one of the two "centres of action", and also that the dipole's effect is most pronounced in Sept-Nov [11], too late to affect the birds' breeding. On the other hand, much of the equatorial Indian
Ocean shows reduced productivity associated with La Niña (see Fig. 5). However, multi-parameter regression indicates that MEI has an effect beyond that associated with local drops in $\mathrm{CC}$; examination of other conditions, including wind stress curl, has not revealed the mechanism by which MEI's additional effect occurs. A test for a lagged response of 7 months (as expected if Rossby waves propagating near the equator were a factor) showed no improvement in explained variance.

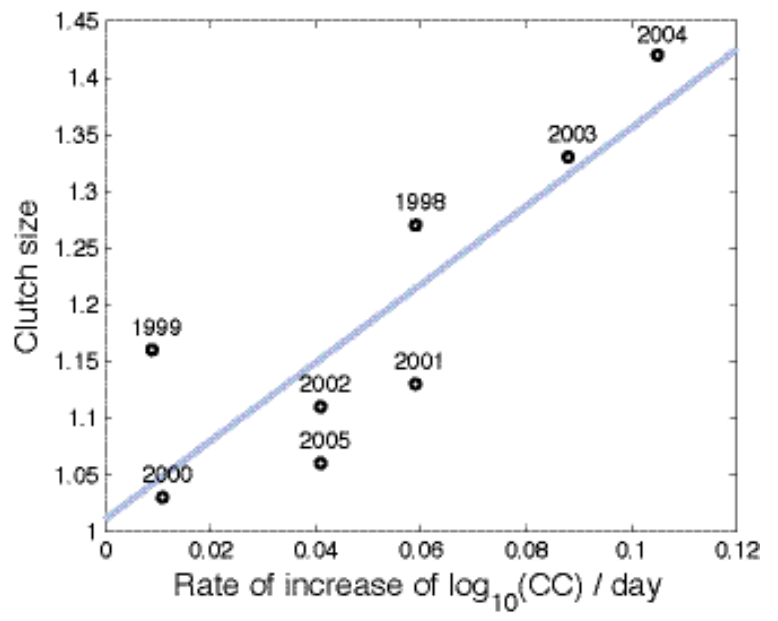

Fig. 4. Mean no. of roseate tern eggs per nest is greatest in the years when the CC around Aride is increasing most rapidly. (Based on Fig. 5 from [2].)

\section{SUMMARY}

A combined look at bird breeding and remote-sensing of phytoplankton has revealed several interesting results. Whilst egg-laying during spring is found for most birds at high latitudes, we have found that one species adopts 3 different strategies on different islands within the Indian tropics. The sooty tern has the expected winter/spring breeding on Europa and Bird Island, but summer breeding on Juan de Nova, and non-seasonal on Lys. The particular oceanic factors permitting more frequent breeding on Lys are not clear, as the SST and CC have strong seasonal cycles.

In a parallel study on Aride, roseate terns are found to adjust their breeding dates to match the variations in expected date for the peak in CC. The environmental cues used by the birds to predict the peak in $\mathrm{CC}$ remains to be closely investigated, but could, at least in part, be linked to SST conditions encountered by the birds upon arrival at the colony (end April-early May; see [2]). ENSO had an impact in addition to the associated changes in $\mathrm{CC}$, although again the mechanism is not clear. Initial follow-up work on adult survival (using a ringing scheme) found a correlation between recapture rates during breeding season (May-July) and DMI (although only 5 years' data have been collected) [12]. This suggests that, for adults staying within the Western Indian Ocean during the non-breeding season 
(Sept-April), the state of the climate summarised by the Indian Ocean Dipole does impact on their fitness, and ultimately on their ability to return for breeding. These investigations on both seasonal cycles and interannual variations show significant connections between changes in $\mathrm{CC}$ and the viability of island colonies of terns, and act as a pointer to how long-term climate change could rapidly affect top marine predators in the ecosystem.

\section{ACKNOWLEDGEMENTS}

We are grateful to NASA/GSFC for the processing and provision of the SeaWiFS data under the progrmme 'Mission to Planet Earth'.

\section{REFERENCES}

[1] Schott, F.A., and J.P. McCreary, "The monsoon circulation of the Indian Ocean,". Prog. Oceanogr. 51, 1-123, 2001

[2] Monticelli, D., J.A. Ramos, and G.D. Quartly, "Effects of annual changes in primary productivity and ocean indices on breeding performance of tropical roseate terns in the western Indian Ocean," Mar. Eco. Prog. Ser., 351, 273-286, 2007.

[3] Ridderinkhof, H., and W.P.M de Ruijter, "Moored current observations in the Mozambique Channel," Deep Sea Res. II 50, 1933-1955, 2003.

[4] Quartly G.D., and M.A. Srokosz, "Eddies in the southern Mozambique Channel," Deep Sea Res. II, 51, 69-83, 2004.
[5] Jaquemet, S., M. Le Corre, and G.D. Quartly, "Ocean control of the breeding regime of the sooty terns in the South-West Indian Ocean," Deep Sea Res I, 54, 130-142, 2007.

[6] Feare, C.J., "The biology of the Sooty tern Sterna fuscata in the Seychelles and the effects of experimental removal of its eggs," J. Zool. Lond. 179, 317-360, 1976.

[7] Feare, C.J., "Breeding schedules and feeding strategies of Seychelles seabirds," Ostrich 52, 179-185, 1981.

[8] Jaquemet, S., M. Le Corre, F. Marsac, M. Potier, and H. Weimerskirch," "Foraging habitat of the seabird community of Europa Island (Mozambique Channel)," Mar. Biol. 147, 573-582, 2005.

[9] Boersma, P.D., "Breeding patterns of Galapagos Penguins as indicator of oceanographic conditions," Sci. 200, 1481-1483, 1978

[10] Ashmole, N.P., "The biology of the wideawake or sooty tern Sterna fuscata on Ascension Island," Ibis 103b, 297-364, 1963.

[11] Saji N.H., B.N. Goswami, P.N. Vinayachandran, and T. Yamagata, "A dipole mode in the tropical Indian Ocean," Nature 401, 360-363, 1999.

[12] Monticelli D., J.A. Ramos, S.A. Guerreiro-Milheiras, and J.L., Doucet, "Adult survival of tropical Roseate Terns breeding on Aride Island, Seychelles, Western Indian Ocean," Waterbirds 31 (in press), 2008.

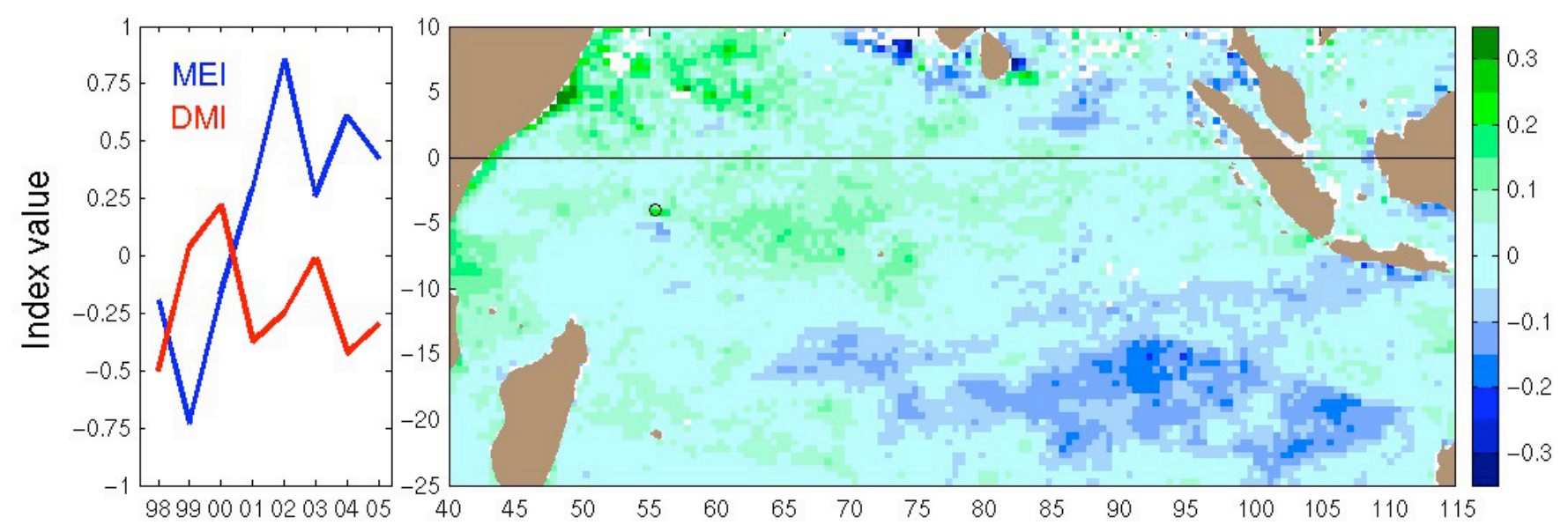

Fig. 5. a) Time series of 2 climatic indices (July-August average for each year) b) Sensitivity of Indian Ocean productivity to El Niño/La Niña: change in $\log _{10} C C$ for unit change in MEI, Aride $\left(4^{\circ} \mathrm{S}, 56^{\circ} \mathrm{E}\right)$ is indicated by a small circle. 